\title{
Spatial variability and mechanisms underlying El Niño-induced droughts in Mexico
}

\author{
Tripti Bhattacharya $\cdot$ John C. H. Chiang
}

Received: 17 September 2013/Accepted: 28 February 2014/Published online: 16 March 2014

(c) The Author(s) 2014. This article is published with open access at Springerlink.com

\begin{abstract}
The El Niño Southern Oscillation plays a key role in modulating interannual rainfall variability in Mexico. While El Niño events are linked to drought in Mexico, uncertainty exists about the spatial pattern and causal mechanisms behind El Niño-induced drought. We use lead/ lag correlation analysis of rainfall station data to identify the spatial pattern of drought associated with the summer before, and the spring following, the peak of warm SST anomalies in the eastern equatorial Pacific. We also use atmospheric fields from the North American Regional Reanalysis to calculate the anomalous moisture budget and diagnose the mechanisms associated with El Niño-induced drought in Mexico. We find that reduced rainfall occurs in Mexico in both the summer before and the spring after a peak El Niño event, especially in regions of climatologically strong convection. The teleconnection in the developing phase of El Niño is primarily driven by changes in subsidence resulting from anomalous convection in the equatorial Pacific. The causes of drought during the decaying phase of El Niño events are varied: in some years, descent anomalies dominate other moisture budget terms, while in other years, drying of the boundary layer on the Mexican plateau is important. We suggest that the latter may result from the interaction of weakened southeasterly winds in the Intra-Americas Sea with high topography along the Atlantic coast of Mexico. Weakened winds are likely driven by a reduced sea level pressure gradient between the Atlantic and the Pacific. Changes in easterly wave activity may contribute to drought in the developing phase of El Niño, but may be less important in the decaying phase of El Niño.
\end{abstract}

T. Bhattacharya $(\varangle) \cdot$ J. C. H. Chiang

Department of Geography, and Berkeley Atmospheric

Sciences Center, University of California Berkeley,

Berkeley, CA 94720, USA

e-mail: tripti@berkeley.edu
Keywords ENSO teleconnections - Mexico · North American monsoon · Rainfall variability

\section{Introduction}

The role of El Niño events in causing summer drought across Mexico is well documented (Magaña et al. 2003; Cavazos and Hastenrath 1990; Seager et al. 2009; Englehart and Douglas 2002; Gochis et al. 2007). ENSO appears to be a dominant driver of interannual variability: variability in Mexican hydroclimate (e.g. rainfall, stream flow) correlates more strongly with ENSO indices than indices of other climatic modes (Gochis et al. 2007). Our own exploratory analyses, using canonical correlation analysis of SST and Mexican rainfall, also show that SST variability in the ENSO region couples with more variability in the precipitation field over Mexico than other regional modes of SST variability (not shown). However, significant uncertainty still exists about the causes of this teleconnection and its spatial signature across Mexico. Reducing this uncertainty is key to understanding the causes of interannual variability and accurately predicting droughts or other natural disasters.

Mexico's summer rainfall is part of a larger monsoonal system extending into the American southwest. Researchers use the term 'North American monsoon' (NAM) to describe the seasonal reversal of surface winds and distinct summer rainy season that occurs in northwest Mexico and the American southwest (Gochis and Berberry 2011). Many conceptual models of monsoons suggest that the seasonal heating of the land surface plays a key role in determining the location and timing convection (Wang et al. 2011). In Mexico, the thermal forcing of the land surface likely interacts with the complex topography, with 
the eastern and western Sierra Madre, the Trans-Mexican Volcanic Belt, and the central Mexican plateau playing a significant role in blocking or lifting low-level atmospheric flow (Mosino-Aleman and Garcia 1974). Winter rainfall brought by the storm tracks also contributes to some regions' rainfall, but represents a small portion of total annual rainfall over much of Mexico's land area.

The connection between rainfall in eastern and central Mexico and the NAM region is not fully understood. Some authors have argued that these two regions are connected within a broad monsoonal region, citing a continuous region of heating and low pressure that extends from central Mexico through the American Southwest in the boreal summer (Tucker 1999; Mosino-Aleman and Garcia 1974). In contrast, others have argued that the traditional NAM region and central Mexico may have different moisture sources and triggers for monsoon onset $(\mathrm{Hu}$ and Feng 2002; Liebmann et al. 2008). Our rainfall data primarily comes from sites in central and southern Mexico. However, for the purposes of this study, we make no a priori distinctions between different regions of Mexico.

Our research is motivated by two main questions:

1. What is the spatial signature associated with El Niño induced drought in Mexico, and what processes are responsible for this spatial pattern? Caso et al. (2007) noted that the correlation between the SOI and summer rainfall anomalies on Mexico's Pacific coast shows a latitudinal gradient, decreasing towards the north of the country. Similarly, Seager et al. (2009) analyzed gridded precipitation data, and suggested that El Niño events increase rainfall in northern Mexico while decreasing rainfall in southern Mexico. Englehart and Douglas (2002) showed that different regions of Mexico exhibit different correlation with ENSO indices. Relatively few studies have explored the causes of this spatial variation in the response of Mexican rainfall to ENSO.

2. Can we shed light on the mechanism underlying the ENSO teleconnection to Mexican summer precipitation? Gochis et al. (2007) highlighted two possible mechanisms by which El Niño events induce drought in Mexico: the first hypothesizes that El Niño events warm SSTs in the eastern Pacific and the tropical Atlantic, reducing the land-sea thermal contrast, and therefore reducing onshore moisture convergence. Turrent and Cavazos (2009) supported this conceptual model by showing that monsoon onset date and moisture convergence over the NAM region is strongly linked to the land-sea thermal contrast. A second mechanism proposes that a developing El Nino event results in anomalous descent over Mexico and Central America, effectively suppressing convection. Giannini et al. (2001) documented this phenomenon in the Caribbean during the summer before a peak El Niño event, and by Seager et al. (2009) in a modeling study for Mexico. This subsidence may be driven by the ability of anomalous convection in the eastern equatorial Pacific to warm the tropical troposphere, suppressing convection in remote tropical regions, although other mechanisms may drive subsidence (Chiang and Sobel 2002). Few observational studies have evaluated the relative importance of the 'land-sea thermal contrast' versus the 'anomalous subsidence' mechanisms in causing drought in different regions of Mexico.

We assess the intraseasonal evolution of the spatial pattern of ENSO-induced drought using lead and lag correlation analysis. This analysis also helps us distinguish between the changes in the teleconnection in the developing versus the decaying phase of anomalously warm Niño 3.4 region SSTs. Second, we use a diagnostic approach to shed light on the mechanisms underlying drought by analyzing the anomalous moisture budget associated with the 1997-1998 El Niño event. We then analyze the composite moisture budget anomalies for El Niño events from 1979 to 2007, in order to see how the dynamical mechanisms associated with rainfall anomalies in Mexico may differ across El Niño events.

\section{Data sources and methods}

\subsection{Precipitation data}

Precipitation station data comes from the Instituto Mexicano de Tecnologia del Agua (IMTA), which oversees monitoring of water resources in Mexico. In 2008, IMTA created ERIC III, a database containing all available meteorological station data from 1900 to 2008. Station data are reported on a daily basis in units of total daily precipitation in $\mathrm{mm}$. We extracted 96 stations from across Mexico's land surface with continuous coverage from 1949 to 1999 , a time period chosen to maximize station coverage, and aggregated daily measurements to monthly rainfall totals for all months of the year. Retained stations had an average of 570 monthly values over the 612- month time period, without any instances where values were missing from more than $25 \%$ of the stations for a given month. We created standardized anomalies of monthly data to account for spatial variance in the monthly total precipitation at different stations. The dataset contains fairly consistent spatial coverage across Mexico's area, although coverage is best for central Mexico, and the Yucatan does not contain any stations with sufficient coverage for this time period (Fig. 1).

We used two approaches to reconstructing missing monthly values: first, missing values were replaced with the 


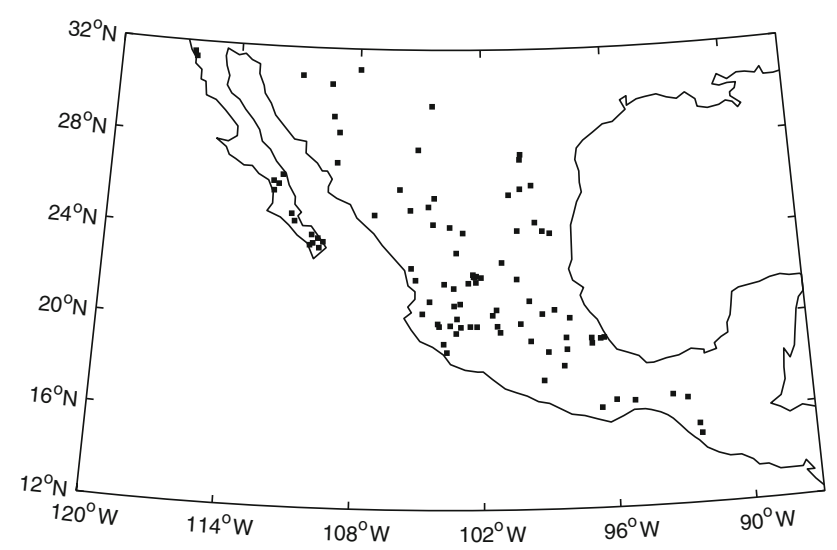

Fig. 1 Location of rainfall stations used in this study, comprising 96 stations in total

average of all other stations' standardized rainfall anomalies, as this type of area-averaged rainfall index can capture the broad features of interannual rainfall variability. In a separate analysis, we used principal component analysis (i.e. EOF analysis) to reconstruct missing monthly values. PCA uses the covariance matrix between available stations' data to derive principal components, time series created from linear combinations of the available data (projected onto the eigenvectors of the covariance matrix) that summarize main patterns of variability in the dataset. By projecting the eigenvectors onto these principal components, we can reconstruct the station data, filling in any gaps.

Exploratory plots comparing original station data with data gaps, the dataset with missing values replaced by an all-station average anomaly, and the station data reconstructed using PCA analysis suggest that all techniques produced time series with similar seasonal and interannual trends (not shown). For further analysis, we chose to use the station data reconstructed using PCA.

\subsection{Surface and atmospheric fields}

We use the Nino 3.4 index, which consists of SST anomalies averaged over a region spanning $5^{\circ} \mathrm{S}-5^{\circ} \mathrm{N}$ and $170^{\circ}-$ $120^{\circ} \mathrm{W}$, as an index of ENSO variability (Trenberth 1997). SST data was obtained from the ERSST version 3 dataset, described in Smith et al. (2008), which is part of NOAA's operational surface temperature analysis.

To obtain $0.5^{\circ}$ grid cell resolution for atmospheric fields over Mexico, we used the North American regional reanalysis (NARR), a data reanalysis project restricted to the domain over North America (Mesinger et al. 2006). The NARR provides $3 \mathrm{~h}$, daily, and monthly climate data for the period from 1979 to the present by assimilating observations into a regional climate model (the NCEP Eta model). Like global reanalyses, the NARR assimilates observational data on temperature, wind, moisture, and pressure, but the NARR incorporates additional datasets and assimilates hourly precipitation observations, satellitederived radiances, near surface wind and moisture, sea and lake ice, and surface temperature. The assimilation of precipitation data and improved hydrological modeling makes the NARR useful for answering questions about regional hydroclimate (Mesinger et al. 2006).

We also use fields of temperature, specific humidity, geopotential height, and vertical velocity (omega) at each pressure level, as well as precipitation and evaporation from the NARR from 1979 to 2010. Derived variables, like moist static energy or moisture flux convergence, were either obtained from the reanalysis using native fields, or calculated using standard formulae. Calculations are detailed below for each derived field.

\section{Lead and lag correlation analysis}

We first focus on clarifying the spatial pattern of the ENSO teleconnection to rainfall in Mexico. El Niño events tend to peak in the boreal winter, but can have distinct influences on regional precipitation in both their developing phase and their decay phase. To clarify these signals in Mexico, we correlated the DJF Niño 3.4 index with rainfall and SST anomalies in the year prior to DJF (year 0), as well as with rainfall and SST anomalies in the year following DJF (year +1$)$. Mexico exhibits distinct intraseasonal variation in summer rainfall, with a mid-summer drought, the canicula, in July or August (Peralta-Hernandez et al. 2008). There is also some evidence of intraseasonal changes in the teleconnections between Mexican and Central American rainfall and large-scale climatic modes (Gochis et al. 2007; Giannini et al. 2001). Moreover, Englehart and Douglas (2002) regionalized JJAS rainfall in Mexico and found that regional differences in Mexican precipitation were largely explained by intraseasonal differences in the persistence of rainfall. In turn, these regions' rainfall seemed to exhibit different correlations with the Nino 3.4 index. To clarify these patterns, we analyze bi-monthly precipitation anomalies for May-June (MJ), July-August (JA), and September-October (SO) to accurately capture seasonal changes in precipitation and analyze potential intraseasonal changes in the ENSO teleconnection.

In Figs. 2 and 3, statistical significance at the $95 \%$ level is calculating via resampling to generate a distribution for the correlation coefficient. We chose this technique in order to account for the highly non-Gaussian distribution of rainfall anomalies.

\subsection{Pattern in year 0}

Figure 2 shows the SST and rainfall pattern associated with year 0 . As we might expect, we see the development of 

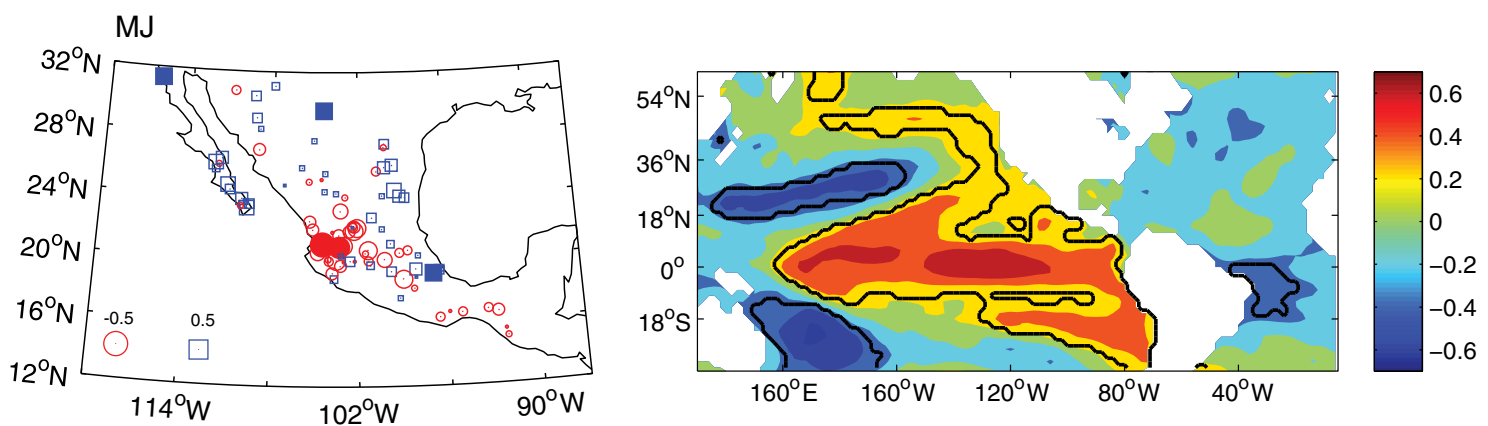

$\mathrm{JA}$
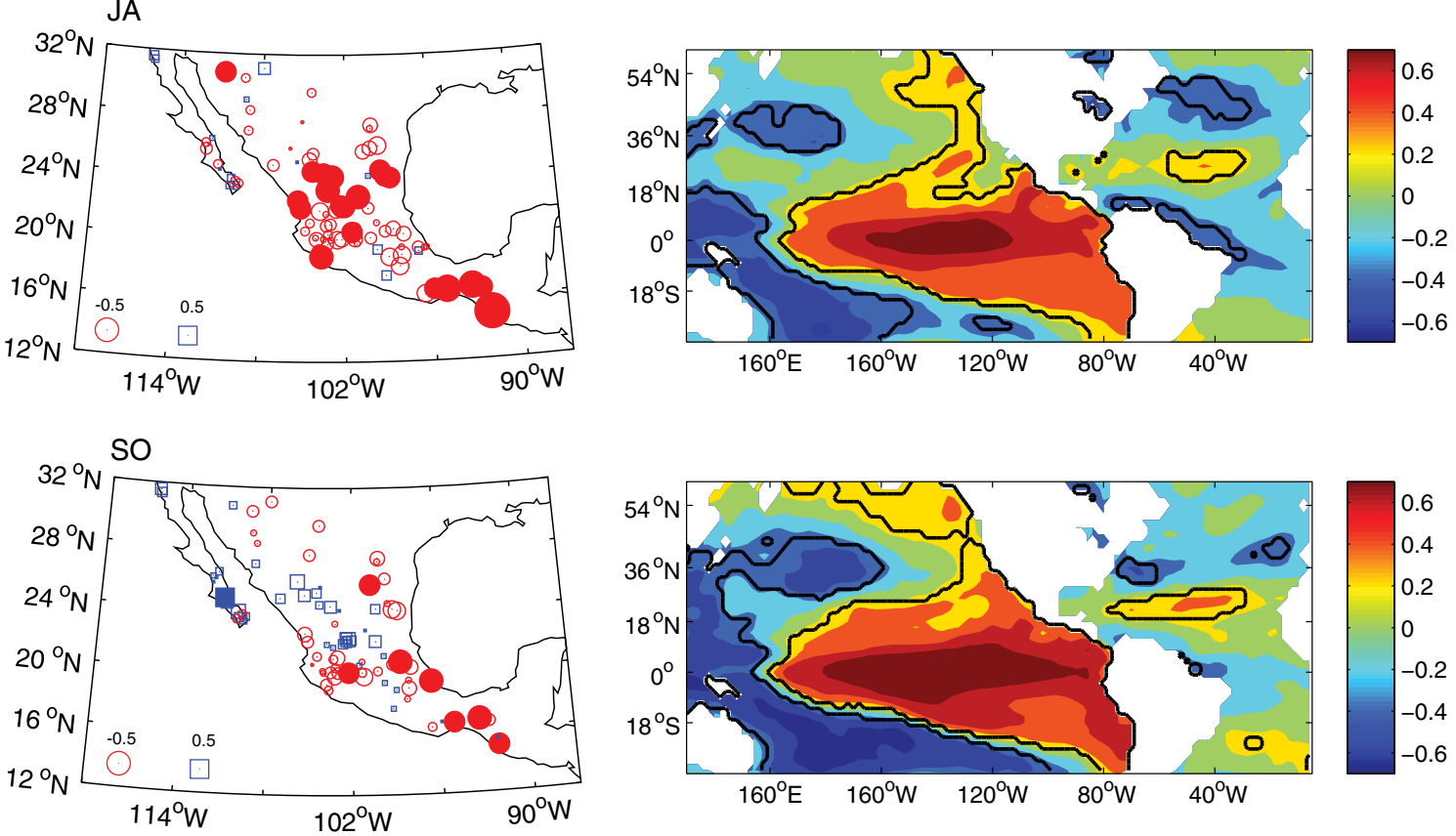

Fig. 2 Correlations between DJF Nino 3.4 index and precipitation and SST anomalies for year 0. Station markers are scaled to the magnitude of the correlations, with blue squares representing positive correlations and red circles representing negative correlations. For

strong warm anomalies in the eastern equatorial Pacific. There is also a slight warming in the tropical Atlantic in SO. This may identify the beginning of a delayed warming of tropical Atlantic SSTs that occurs following a peak El Niño event (Xie and Carton 2004; Enfield and Mayer 1997). The pattern of rainfall anomalies shows both significant positive and negative rainfall anomalies in $\mathrm{MJ}$, primarily negative rainfall anomalies across all of Mexico's land area in JA, and negative rainfall anomalies in central and southern Mexico in SO.

\subsection{Pattern in year +1}

Figure 3 shows the patterns associated with the DJF Niño 3.4 index in year +1 . In MJ, we see warm waters in the eastern equatorial Pacific, and significant warming in the tropical Atlantic, which is consistent with the results of previous studies reference, markers representing correlations of 0.5 are in the left corner. Solid-colored station markers and areas within the solid black contour of SST indicate significant correlations at $95 \%$, determined via resampling

(Xie and Carton 2004; Chiang and Lintner 2005; Chiang and Sobel 2002; Enfield and Mayer 1997). In JA and SO, the pattern breaks down and we see the beginning of cool conditions in the equatorial Pacific, representing the development of negative SST anomalies in the central equatorial Pacific in the year following the peak of warm SST anomalies. Rainfall anomalies in Fig. 3 suggest that negative rainfall anomalies associated with an El Niño event persist into the year following spring: the MJ rainfall pattern shows negative anomalies confined to southern Mexico, despite warming the northern tropical Atlantic. In JA and SO, we see strong positive rainfall anomalies, likely associated with the development of anomalously cool conditions in the eastern equatorial Pacific.

The persistence of negative precipitation anomalies to the spring following a peak El Niño is surprising, as we might expect warmed SSTs to increase boundary layer moisture and moisture convergence over Mexico, 

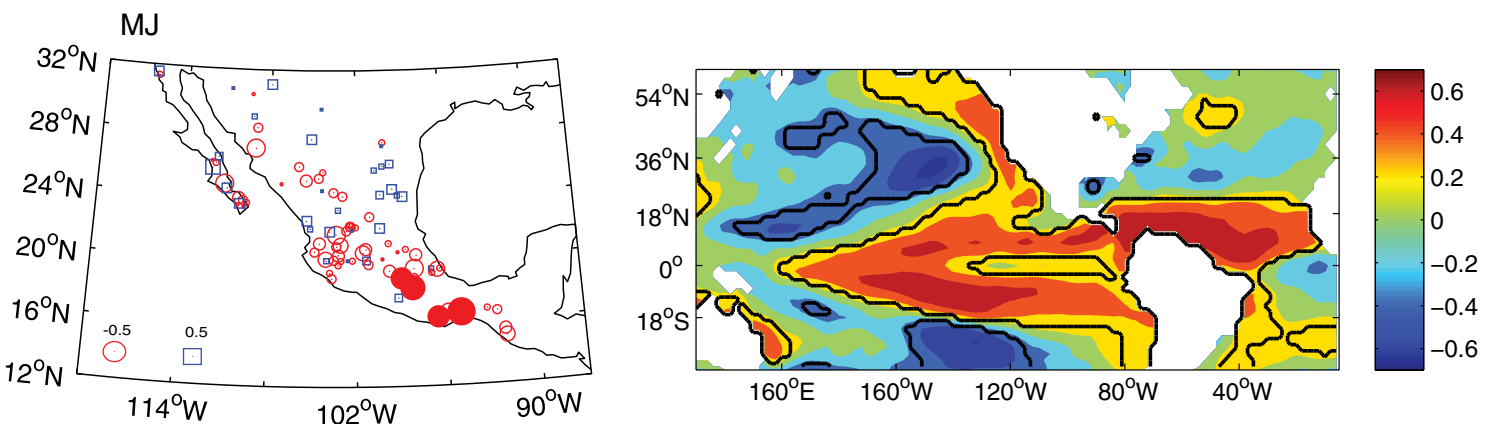

JA
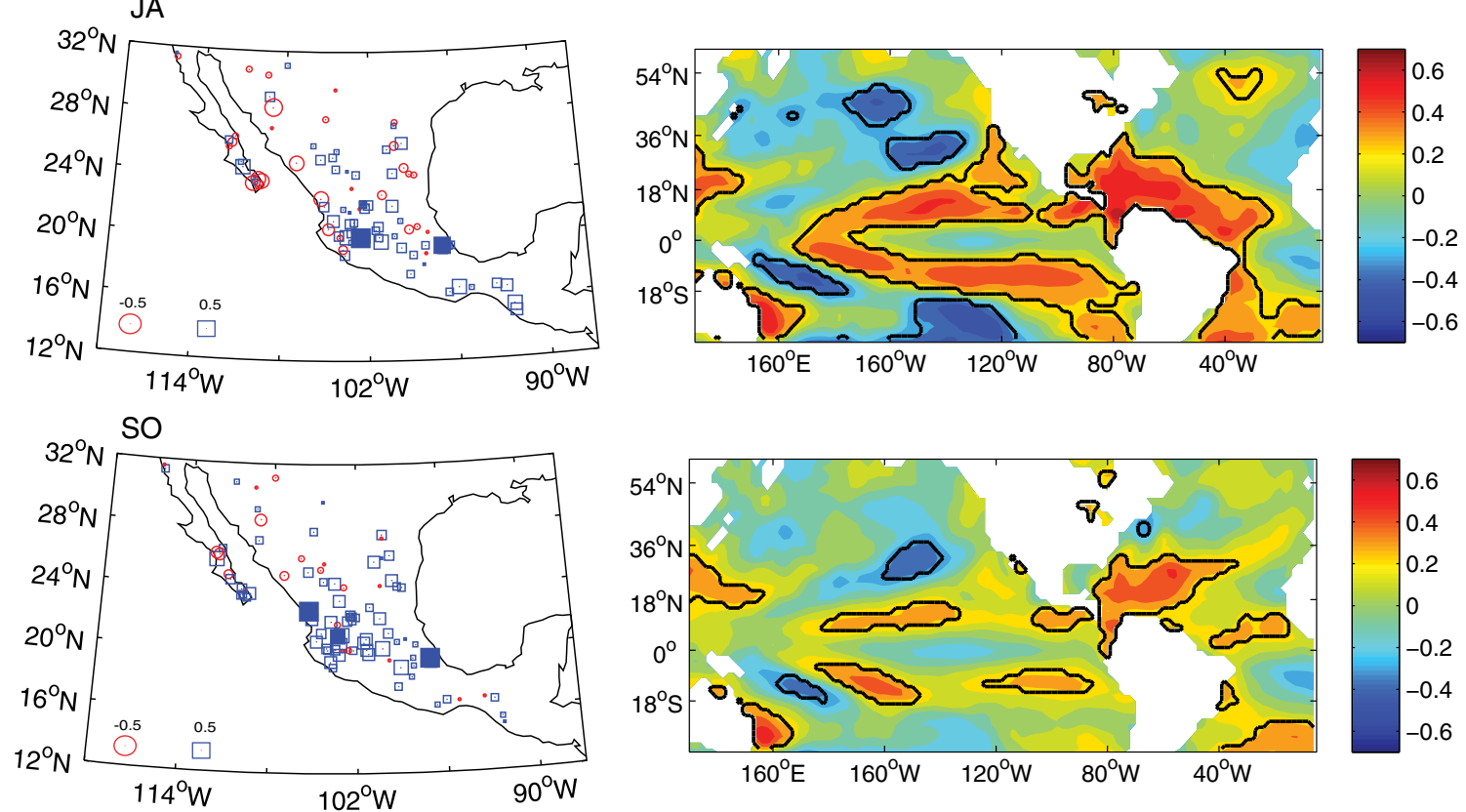

Fig. 3 As in Fig. 2, but showing the correlations between DJF Nino 3.4 index and precipitation and SST anomalies for year +1

increasing precipitation (Giannini et al. 2001). However, in the Caribbean, the positive rainfall anomaly in the spring following a peak El Niño documented by Giannini et al. (2001) is weaker or absent in the period from 1979 to 1999 as a result of the influence by the NAO. Running correlations between precipitation anomalies in Mexico and the leading DJF Nino 3.4 index do provide some evidence for decadal changes, as the drought signal in the spring following a peak El Niño is strongest in the period following 1976, although it is generally present throughout the instrumental record used in this study (not shown). Possible causes of this interdecadal change in the ENSO teleconnection to the broader Central American region have been linked to low-frequency changes in the North Atlantic or the North Pacific, and have been addressed elsewhere (Hu and Feng 2008; Giannini et al. 2001; Englehart and Douglas 2002). These previous studies demonstrate statistical relationships between the ENSO signal in spring rainfall and low-frequency changes in other atmospheric modes. Instead of focusing on the sources of interdecadal change, we choose to focus on diagnosing the mechanisms associated with rainfall anomalies in the developing and decaying phase of El Niño events. We therefore focus on the time period from 1979 onwards, after any interdecadal changes likely took place, as it allows us to take advantage of high-resolution reanalysis data over North America from the NARR. Understanding the atmospheric mechanisms responsible for drought can shed light on mechanisms by which low-frequency climate modes may alter the ENSO teleconnection to Mexico.

\subsection{Spatial pattern of rainfall anomalies}

Before addressing the physical mechanisms behind the ENSO teleconnection, we note that in our leading and lagging correlation analysis, the location of statistically significant negative correlations between the Niño 3.4 index and rainfall evolves spatially from May through October. These anomalies largely occur in southern Mexico in the early season (MJ), with the strongest signal 
occurring in year +1 , occur throughout Mexico in JulyAugust (in year 0 ), and are again confined to southern Mexico in SO (year 0). This pattern appears to reflect seasonal changes in the mean location of convection across Mexico, with the location of moisture convergence and convection following the location of peak heating of the land surface. To visualize changes in the atmospheric energy available for convection, we plot climatological moist static energy, integrated between 750 and $500 \mathrm{mb}$, as it evolves from May through October.

Moist static energy (MSE) reflects the energy from sensible heat, latent heat, and geopotential in a parcel of air (Holton 2004):

$M S E=g z+C p T+L q$

where $g$ is acceleration due to gravity, $z$ is height, $C p$ is the specific heat of air at constant pressure, $T$ is air temperature, $L$ is the latent heat of vaporization, and $q$ is the specific humidity. Privé and Plumb (2007) showed that the location of maximum ascent and rainfall in a meridional monsoonal circulation is co-located with the maximum in sub cloud moist static energy. Mosino-Aleman and Garcia (1974) also showed that, in Mexico, precipitation tends to follow the northward propagation of peak temperatures, and peaks slightly south of the temperature maximum.

Plots of climatological moist static energy show the northward progression of the location of peak terrestrial moist static energy from MJ to JA (Fig. 4). This pattern mirrors the northward progression of ENSO-related rainfall anomalies observed in correlation analysis. This suggests that while El Niño events have a largely negative effect on summertime convective activity across much of Mexico, the relationship appears stronger in regions where, climatologically, we would expect strong convection. These regions shift seasonally following changes in the location of maximum moist static energy, which may be driven by the heating of the land surface and enhanced by the advection of moist static energy. This is consistent with the analysis of Tucker (1999), who showed that a zone of low pressure extends across the Mexican altiplano and into the southwest United States in July, during the time of peak summer precipitation. We next focus on analyzing the atmospheric processes that contribute to drought during El Niño events.

\section{Moisture budget analysis of the 97-98 El Niño drought}

\subsection{Moisture budget analysis}

Causes of precipitation change can be diagnosed by analyzing the anomalous moisture budget associated with

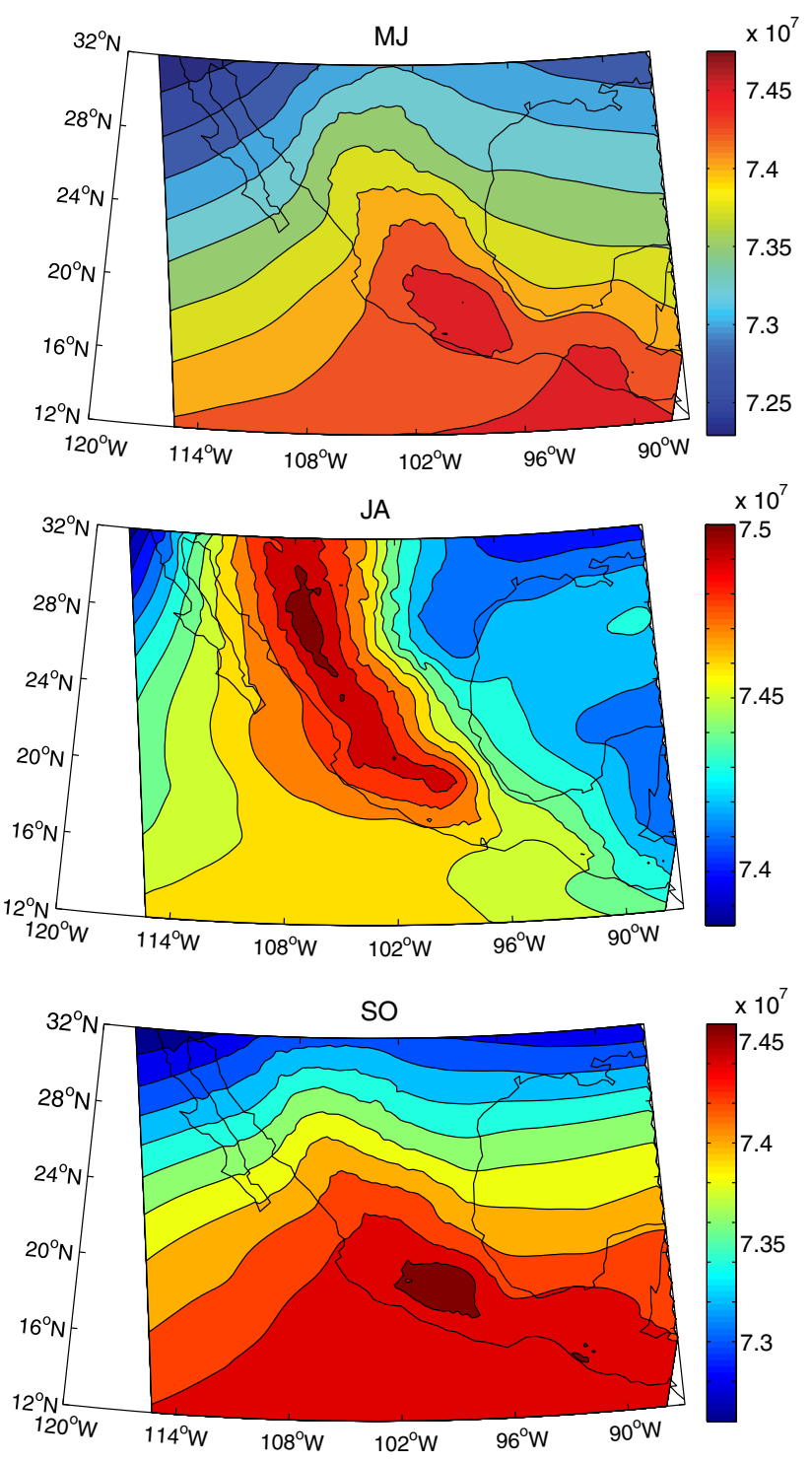

Fig. 4 Bimonthly climatologies of moist static energy integrated between 750 and $500 \mathrm{mb}$, in $\mathrm{J} / \mathrm{kg}$, for MJ, JA, and SO, showing the development of a strong gradient of moist static energy during the peak summer rainy season over Mexico's land surface

precipitation anomalies (Chou et al. 2009; Chou and Neelin 2004). In this case, we analyze the anomalous moisture budget associated with the summer before (year 0 ) and the spring following (year +1) of the 1997-1998 El Niño. Subsequently, we perform this analysis for all El Niño events between 1979 and 2007 to analyze spatially-averaged composites of anomalous moisture budgets. Following Chou et al. (2009), the anomalous moisture budget equation is:

$$
\begin{aligned}
P^{\prime}= & -\left\langle\bar{w} \partial_{p} q^{\prime}\right\rangle-\left\langle w^{\prime} \partial_{p} q\right\rangle-\langle v \cdot \nabla q\rangle \prime+E^{\prime} \\
& + \text { residual terms }
\end{aligned}
$$

where $P$ is precipitation in $\mathrm{W} \cdot \mathrm{m}^{-2}, \omega$ is vertical velocity, $q$ is specific humidity in $\mathrm{J} / \mathrm{kg}, \mathbf{v}$ is horizontal velocity, and $E$ 
is evaporation. (-) represents mean climatological conditions, whereas $(I)$ represents the departure from the climatology associated with the 1997-1998 El Niño. We separate $\langle v \cdot \nabla q\rangle^{\prime}$ into the component associated with anomalous winds, $\langle v \prime \cdot \overline{\nabla q}\rangle$, and the component associated with an anomalous moisture gradient, $\left\langle\bar{v} \cdot(\nabla q)^{\prime}\right\rangle$. The vertical integral, given by \langle\rangle , represents a mass integration from surface pressure to $300 \mathrm{hPa}$. Conceptually, Eq. 1 allows us to separate precipitation anomalies into components associated with climatological vertical velocity and an anomalous vertical gradient of moisture $\left(\bar{w} \partial_{p} q^{\prime}\right)$, called the direct moisture effect; anomalous ascent and climatological moisture $\left(w^{\prime} \partial_{p} \bar{q}\right)$, or the dynamical feedback; anomalous horizontal advection $(\mathbf{v} \cdot \nabla q \prime)$; anomalous evaporation; and residual terms that include the contribution of transient terms and non-linear terms. In calculating the magnitude of each of these terms, we are primarily interested in evaluating the relative magnitude of each term's contribution to precipitation anomalies in order to assess the relative importance of different mechanisms. Given the limitations of reanalysis data and our use of monthly average terms, discussed in the next section, our calculated budget is unlikely to close.

\subsection{Limitations of approach}

We use monthly fields from the NARR to calculate the terms in (1). Our approach has several limitations: first, errors are introduced from interpolating from the model's native grid to the Lambert output grid in calculating horizontal advection (Mesinger et al. 2006). There is a NARR native moisture flux convergence (MFC) term available, where

$P-E \approx M F C$

assuming that changes in atmospheric water storage are relatively small. However, with this term we cannot separate out contributions from vertical and horizontal advection. To assess this source of error, we compare the sum of terms on the right side of (1), minus evaporation, to the native calculations of moisture flux convergence in the NARR. Other limitations of the NARR stem from overactive evaporation, excessive moisture flux convergences, some datasets reflecting patterns associated with national borders, and errors resulting from the redistribution of moisture in the precipitation assimilation scheme (Nigam and Ruiz-Barradas 2006; Mesinger et al. 2006; Ruane 2010). Finally, our use of monthly averages prevents an estimation of transient and non-linear terms, which may have a large contribution to precipitation anomalies.

However, the NARR represents the highest resolution reanalysis product for our study domain, is specifically suited to studies of regional hydroclimate, and performs better than global reanalyses (e.g. ERA-40 and NCEP) in studies of the water budget over North America (Nigam and Ruiz-Barradas 2006). In addition, we are primarily interested in estimating the relative importance of different terms in Eq. (1), which may still be a valid exercise in spite of inaccuracies in our budget calculations. In the next section, we analyze the rainfall anomalies and anomalous moisture budget associated with the developing (JAS 1997) and decaying (MJ 1998) phases of the 1997-1998 El Niño.

\subsection{Rainfall anomalies (1997-1998 El Niño)}

The NARR precipitation field documents significant precipitation anomalies in JAS 1997 and MJ 1998, although the spatial patterns of drought differ (Fig. 5). In JAS 1997, the strongest rainfall anomalies occur in central Mexico, with weaker anomalies in southern Mexico and the Yucatan. In MJ 1998, a region of anomalous rainfall occurs primarily in eastern Mexico, with weaker anomalies in northwest Mexico. Some areas of the Yucatan and Caribbean appear to have weakly positive rainfall anomalies. In the next two sections, we analyze the anomalous moisture budget associated with these anomalies. Figure 6 displays the terms in the anomalous moisture budget for JAS 1997 and MJ 1998 averaged between $95^{\circ}-105^{\circ} \mathrm{W}$ and $16^{\circ}-28^{\circ} \mathrm{N}$.

\subsection{Developing phase of El Niño (JAS 1997)}

The dynamical feedback term is the dominant contributor to negative precipitation anomalies, since other terms are an order of magnitude smaller (Fig. 6). The next two largest terms are changes in evaporation $\left(E^{\prime}\right)$, which oppose negative precipitation anomalies, and anomalous advection associated with anomalous winds $\langle v \prime \cdot \overline{\nabla q}\rangle$, which weakly contributes to negative precipitation anomalies. The sum of the terms on the right side of Eq. (1) accounts for $90 \%$ of the change in precipitation. To further evaluate our budget calculations' performance we compare the sum of the dynamical feedback, the direct moisture effect, and anomalous advection (i.e. the right side of Eq. (1) without evaporation) to the anomalous moisture flux convergence calculated from the native NARR fields. We note that our calculations deviate by $11 \%$ from the anomalous moisture flux convergence calculated from the native NARR fields, suggesting our calculations are generally accurate, at least to an order of magnitude (not shown). Figure 7 shows the spatial pattern of the dominant terms in the anomalous moisture budget for JAS 1997.

The dynamical feedback term is the dominant contributor to negative rainfall, indicating anomalous descent (positive $w$ ). This term is especially strong in central and southern Mexico. The dominance of this term is consistent 
(a)

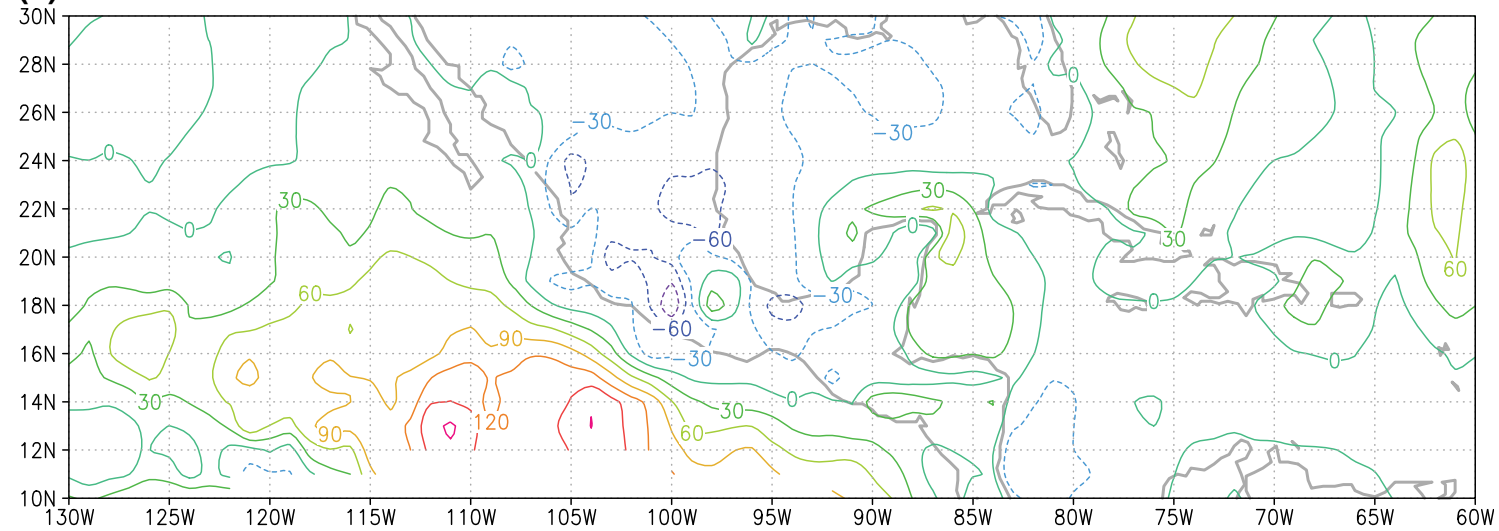

(b)

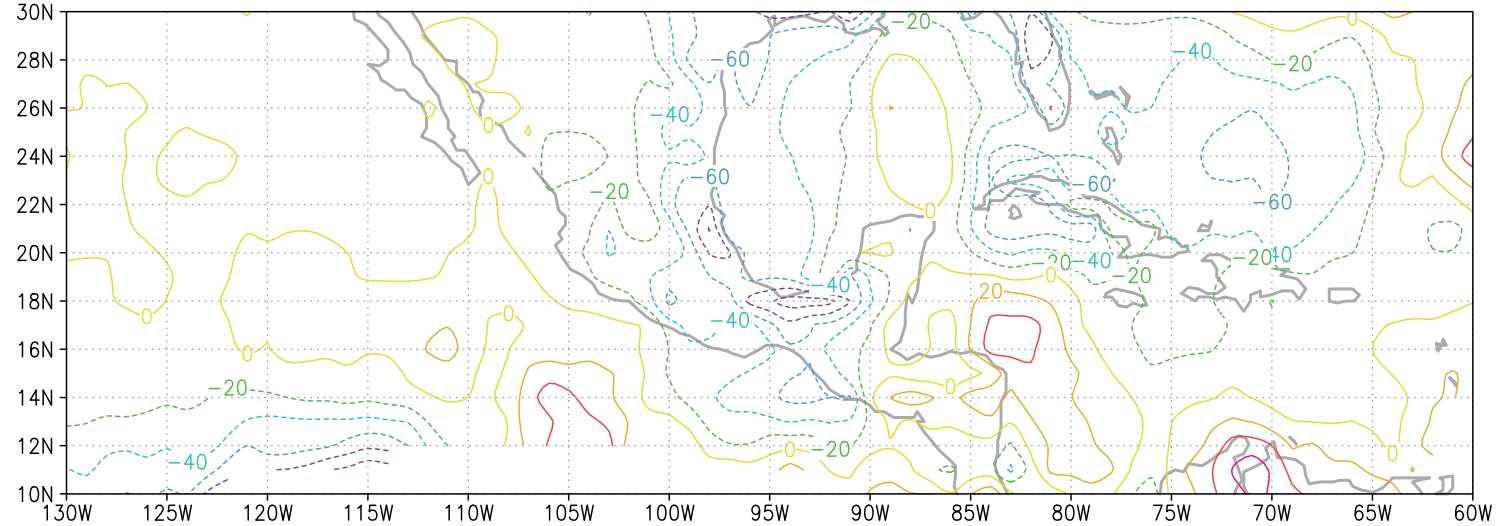

Fig. 5 Rainfall anomalies in (a) JAS 1997 and (b) MJ 1998 from the NARR, in $\mathrm{W} \mathrm{m}^{-2}$. Negative contours are dashed

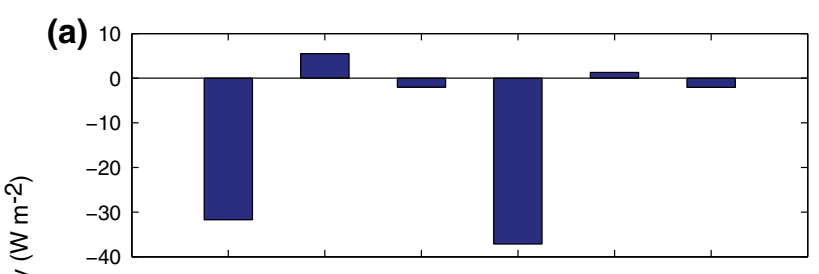

(b)

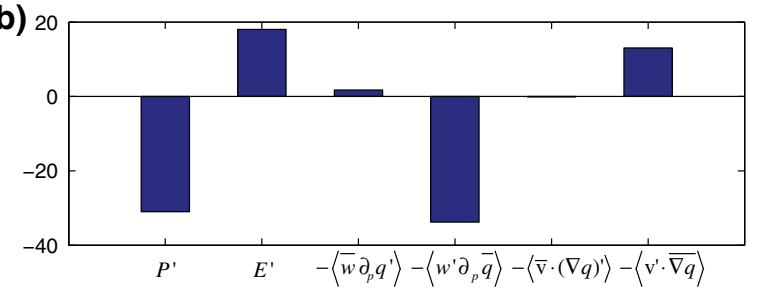

Fig. 6 Area-averaged anomalous moisture budget for (a) JAS 1997 and (b) MJ 1998, see text for details

with the 'anomalous Walker circulation' model of the ENSO telconnection identified in previous research (Seager et al. 2009; Xie and Carton 2004; Saravanan and Chang 2000). In contrast, the alternate conceptual hypothesis suggests that El Niño alters the land-sea thermal contrast, reducing onshore winds and moisture convergence (Gochis et al. 2007). However, anomalous moisture advection plays a much smaller role in precipitation anomalies according to our budget calculations, at least over the majority of the spatial domain of our analysis.

In our area-averaged calculation, the anomalous advection due to anomalous winds makes a very weak negative contribution to precipitation (Fig. 6). The spatial pattern associated with this term shows a weak negative contribution along Mexico's east coast (Fig. 7). This pattern may result from the influence of El Niño events on moisture fluxes from the Intra-Americas Seas. The enhanced interbasin gradient of SLP associated with El Niño events is known to enhance easterly moisture transport from the Atlantic to the Pacific, decreasing precipitation over the Intra-American Seas and eastern Mexico (Mestas-Nuñez et al. 2007). In the next section, we analyze the changes associated with the decaying phase of the 1997-1998 El Niño.

\subsection{Decaying phase of El Niño (MJ 1998)}

The area-averaged anomalous moisture budget in the decaying phase of the El Niño event also indicates the 

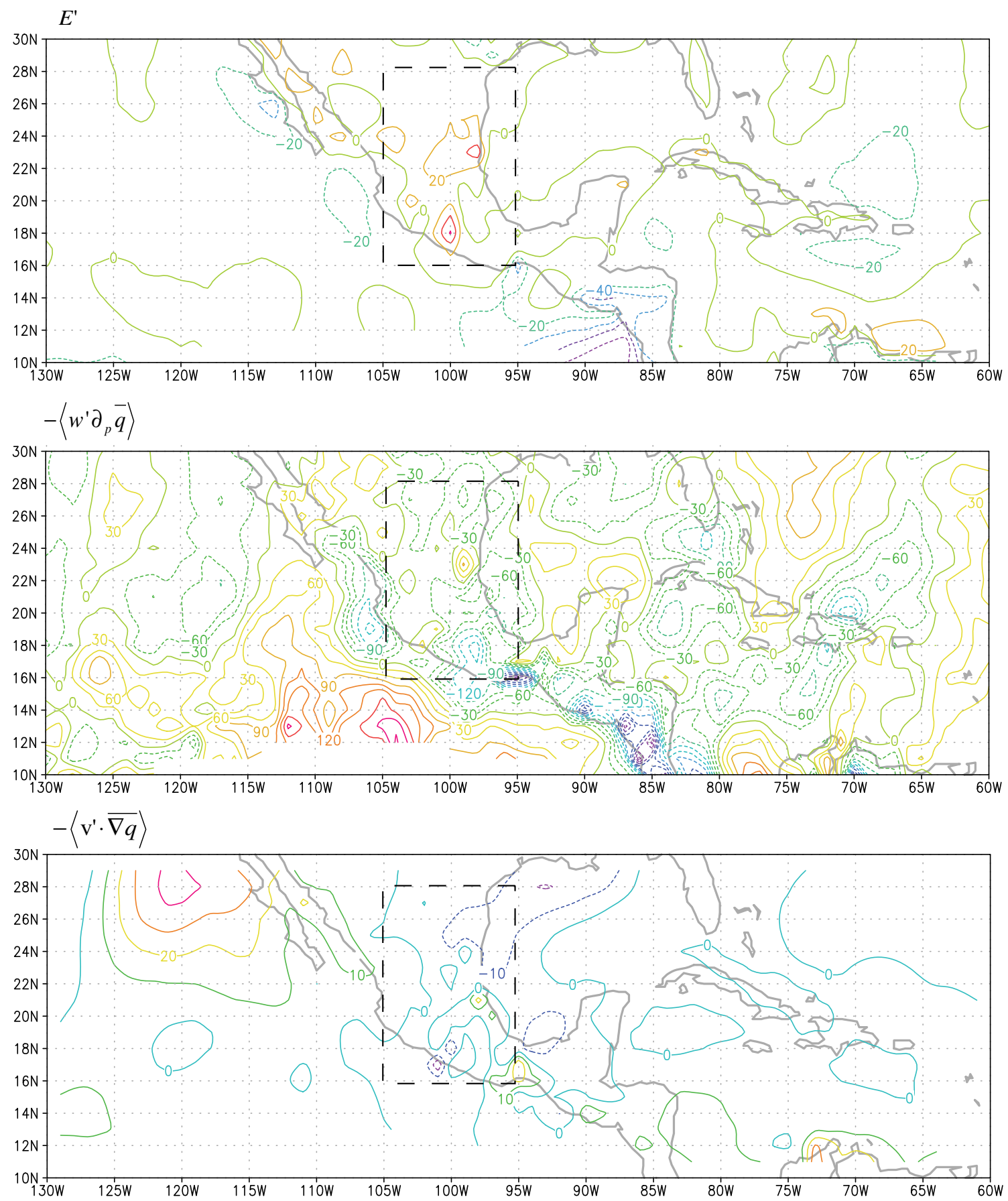

Fig. 7 The dominant terms in the anomalous moisture budget for JAS 1997. Rectangle indicates averaging area for Fig. 10. Anomalies in $\mathrm{W} \mathrm{m}^{-2}$

dominance of the dynamical feedback (Fig. 6). The spatial patterns associated with the four dominant terms in the anomalous moisture budget shows that the dynamical feedback term is slightly weaker than in JAS 1997 and is centered in southeastern Mexico (Fig. 8). Anomalous evaporation $\left(E^{\prime}\right)$, the direct moisture effect $-\left\langle\bar{w} \partial_{p} q \prime\right\rangle$, and anomalous advection due to anomalous winds $-\langle v \prime \cdot \overline{\nabla q}\rangle$ oppose this influence. Our calculations underestimate the precipitation change, but are of the correct magnitude and are similar to estimates of anomalous moisture flux convergence (not shown). Interestingly, native MFC calculations from the NARR underestimate the difference between precipitation and evaporation.

Enhanced evaporation over Mexico's land area in the spring following a peak El Nino may result from the tendency of El Nino events to enhance winter precipitation 

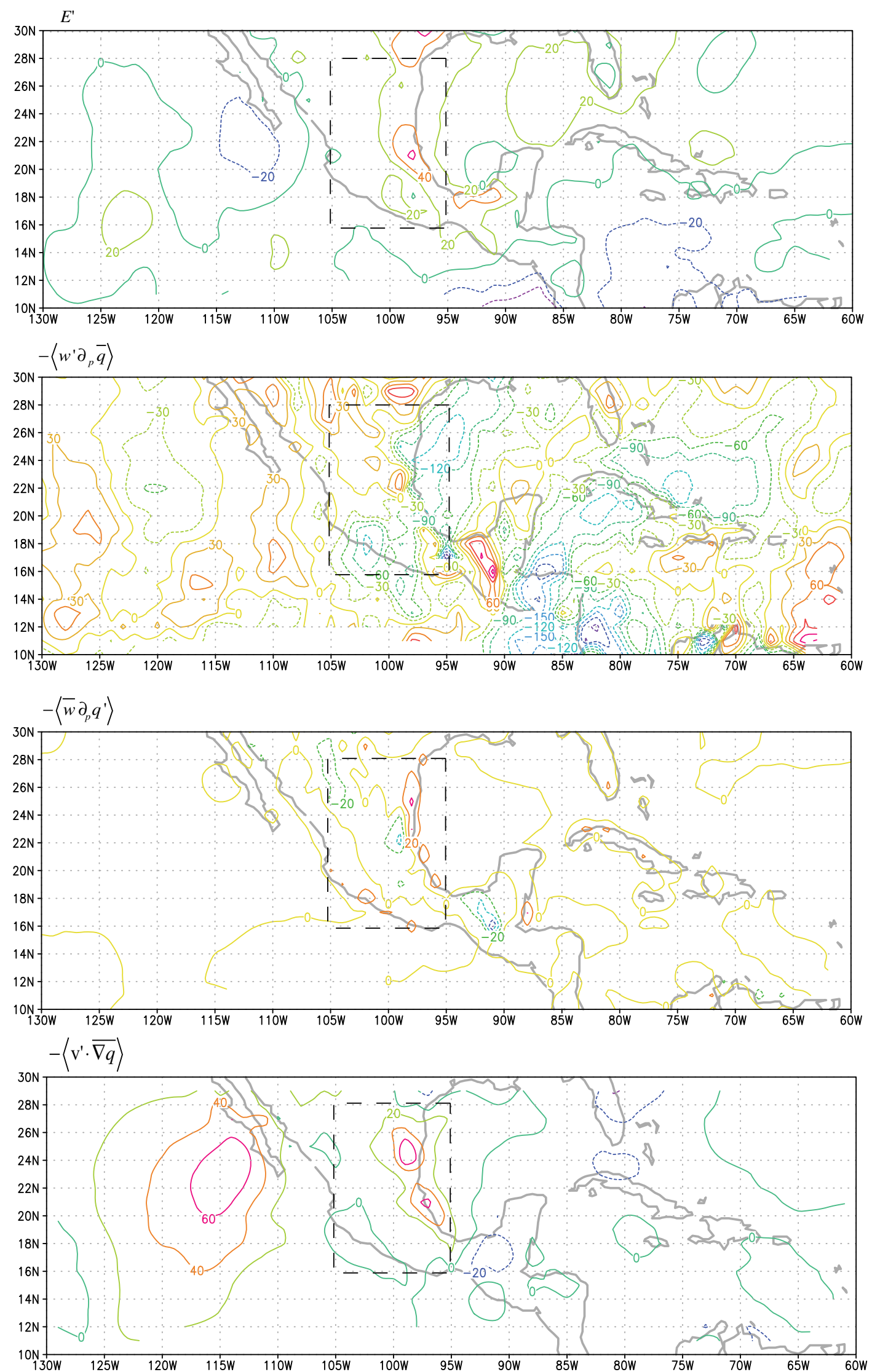

Fig. 8 As in Fig. 7, but for MJ 1998, during the decaying phase of El Nino 
over Mexico, resulting in enhanced soil moisture the following spring (Magaña et al. 2003). We may also expect enhanced evaporation during drought conditions, as suppressed convection and cloud cover enhance surface temperatures. However, evaporation is known to be overactive in the NARR (Nigam and Ruiz-Barradas 2006).

The direct moisture effect opposes negative precipitation anomalies, and is stronger along the east coast of Mexico in MJ 1998 than in JAS 1997. Tropical Atlantic SSTs tend to warm following a peak El Niño as a result of anomalous heat fluxes caused by an El Niño-induced warming of the tropical troposphere (Chiang and Sobel 2002; Lintner and Chiang 2007; Saravanan and Chang 2000). Since boundary layer moisture is tied to underlying SSTs and Mexico derives much of its moisture from the tropical Atlantic and the Intra-Americas Sea, a moistened boundary layer following a peak El Niño event is likely to result in greater moisture over Mexico's land area (DuranQuesada et al. 2010; Mestas-Nuñez et al. 2007). However, the spatial pattern associated with this term is puzzling: while the boundary layer moisture increases along the east coast of Mexico, we observe the drying of the boundary layer inland on the Mexican plateau (Fig. 8). Causes of this pattern are addressed in the next section.

A weak positive contribution to rainfall occurs as a result of anomalous advection associated with wind anomalies in MJ 1998, especially along the east coast of Mexico (Fig. 8). This is opposite in sign to the influence of this term in JAS 1997. Easterly transport from the Atlantic to the Pacific over Central America, strongly linked to variations in the Caribbean Low-Level Jet, is sensitive to the interbasin gradient of SLP (Mendez and Magaña, 2010; Muñoz et al. 2008; Wang 2007). In the decaying-phase of the 1997-1998 El Nino, the ENSO-induced warming of the tropical Atlantic may have decreased Atlantic SLP, while a developing La Niña increased tropical Pacific SLP. We discuss this pattern further in the next section. This term, however, is relatively small for MJ 1998. We next assess whether the atmospheric changes associated with the 1997-1998 El Niño event are consistent across several warm ENSO events between 1979 and 2007.

\section{Composite moisture budget analyses and mechanisms for spring drought}

5.1 El Niño composite of anomalous precipitation and moisture budget

ENSO events show a diversity of structures, and it is possible that the mechanisms responsible for anomalous drying over Mexico in 1997-1998 may not be important for other warm ENSO events. To address this uncertainty,

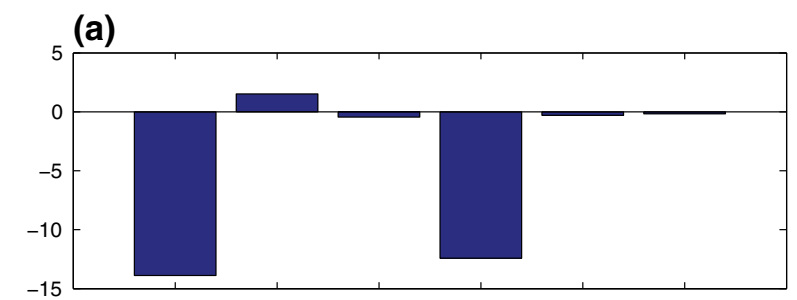

(b)

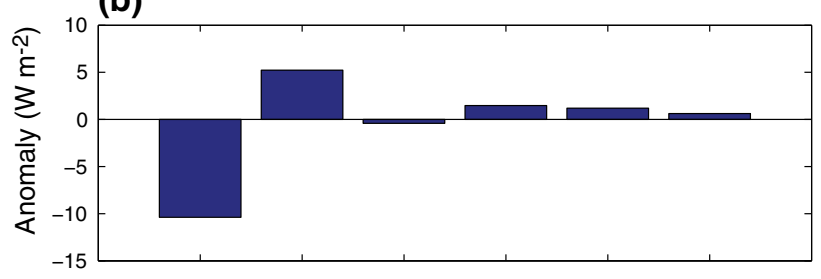

(c)

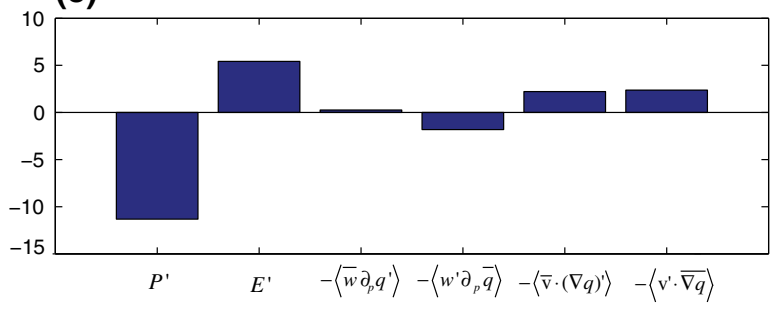

Fig. 9 Area-averaged composite anomalous moisture budgets for different phases of El Niño events from NARR (see text). (a) JAS of year 0 composite; (b) MJ of year +1 composite, and (c) MJ of year +1 composite, eliminating years that exhibit negative SST anomalies in the Niño 3.4 region in MJ

we identified 9 El Niño events between 1979 and 2007, which were defined according to standard techniques as episodes where the 3-month running mean of the Niño 3.4 index exceeds a threshold of $0.5^{\circ} \mathrm{C}$. Using this criterion, we identify El Niño events occurring in: 1982-1983; 1986-1987; 1987-1988; 1991-1992; 1994-1995; 1997-1998; 2002-2003; 2004-2005; and 2006-2007. We then calculated the anomalous moisture budget for the developing year's JAS and decaying year's MJ for each of these events. Figure 9 presents these anomalous budgets as a composite, spatially averaged over the area $95^{\circ}-105^{\circ} \mathrm{W}$ and $16^{\circ}-28^{\circ} \mathrm{N}$.

Figure 9 shows the results of this composite budget analysis. The JAS composite is largely similar to the results from JAS 1997: strong negative rainfall anomalies are almost entirely driven by the dynamical feedback. The situation for MJ, however, is more complicated: the second panel shows the composite moisture budget analysis for all springs in the decaying phase of ENSO events. While the mean precipitation anomaly across all events is negative, other terms seem to cancel to zero across events. This suggests that there is not one dominant mechanism influencing negative rainfall anomalies in the spring following a peak El Niño, and a diversity of responses may be likely. It is also possible that a developing La Niña in May-June 
following some El Niño events may result in positive precipitation anomalies that obscure the drought signal. To assess this possibility, we excluded years where May-June Niño 3.4 SST anomalies are negative (e.g. 1988, 2007) and redid the composite in the third panel of Fig. 9. Results still showed negative rainfall anomalies, and a slightly negative dynamical feedback, but apart from evaporation, moisture budget terms are still very close to 0 . This again suggests that there may be a diversity of mechanisms influencing El Niño-induced spring rainfall reductions in Mexico. We next present the anomalous moisture budget for MJ 2005, a year in which mechanisms apart from the dynamical feedback drive rainfall reductions.

\subsection{Dominant terms in moisture budget for MJ 2005}

In Fig. 10, we show the dominant terms in the anomalous moisture budget for MJ 2005.

The pattern associated with this year, with slightly different spatial patterns, appears common to several years that exhibit negative rainfall anomalies in the spring following a peak El Niño event (not shown). Negative precipitation anomalies occur in central Mexico and off the Atlantic coast of Mexico. While the dynamical feedback is negative offshore, it generally has a positive sign over Mexico's land area. The spatial pattern of precipitation anomalies over land appears to be driven by the spatial pattern of the direct moisture effect, $-\left\langle\bar{w} \partial_{p} q^{\prime}\right\rangle$, and the influence of anomalous advection due to anomalous winds, $-\langle v \prime \cdot \overline{\nabla q}\rangle$. This anomalous advection may result from northwesterly wind anomalies along the east coast of Mexico, and westerly anomalies, primarily across the Isthmus of Tehuantepec, in spring 2005 (not shown). These wind anomalies in turn likely reduce northward and westward moisture transport from the tropical north Atlantic and the Caribbean into the Gulf of Mexico and central Mexico.

The direct moisture effect shows drying of the boundary layer over much of Mexico's interior land area. There are localized areas of moisture increase along the coast, especially on the Pacific coast. Interestingly, the locations of the zero contours very roughly conform to the locations of the mountain chains along the coasts of Mexico, suggesting some effect of topography. We also note that a similar, albeit much weaker, pattern of the direct moisture effect and anomalous winds also occurs in MJ 1998: anomalous advection makes a negative contribution to rainfall in southern Mexico, and the direct moisture effect shows slightly enhanced moisture on Mexico's east coast and drying of the boundary layer of the Mexican plateau (Fig. 8). We next present mechanisms that may be responsible for observed changes in advection and boundary layer moisture in springs following El Niño events.

\section{Role of the Caribbean low-level jet in El Niño- induced rainfall changes}

6.1 Changes in moisture transport by the Caribbean low-level jet

What may be responsible for the spatial pattern of anomalous moisture budget terms observed in MJ 2005? We suggest that the anomalous advection pattern ultimately results from the altered interbasin gradient of SLP between the Atlantic and Pacific: the Caribbean Low Level Jet, a maximum of low-level winds, is important for northward and westward moisture transport out of the Intra-Americas Sea (Mestas-Nuñez et al. 2007). Inter-annual variability of the CLLJ has been linked to the gradient of SLP between the Atlantic and Pacific basins. For instance, in the developing phase of an El Niño event, anomalous convection and low pressure anomalies in the eastern equatorial Pacific enhance easterly wind transport across Central America and enhance the CLLJ (Wang 2007). We suggest the opposite occurs in the decaying phase of a warm ENSO event: warmed Atlantic SSTs after a peak El Niño create negative pressure anomalies that weaken the CLLJ and northward moisture transport into Mexico. Mestas-Nuñez et al. (2007) note a positive correlation between precipitation over Mexico and northward moisture transport out of the Intra-Americas Sea. Figure 11 shows composites of anomalies in the CLLJ index, as defined by Wang (2007), in the developing and the decaying phase of El Niño events between 1979 and 2009. While the signal is strongest in the developing phase of El Niño, with an enhanced low-level jet, we also note that the jet is weaker than average in the springs following peak El Niño events.

Furthermore, we suggest that the interaction of topography and these negative wind anomalies results in the drying of the boundary layer on the Mexican plateau. We note that, roughly, the tendency of low-level airflow to lift over a topographic barrier increases with the strength of the velocity component normal to the barrier, neglecting changes in vertical gradients of temperature and moisture (Wallace and Hobbs 2006). As springs following warm ENSO events exhibit weaker southeasterly winds over the Gulf of Mexico, it is possible that topographic barriers, especially along the Atlantic coast of Mexico, act to block low level flow from lifting over these coastal mountains and transporting moisture to the interior of the country. As a result, we may observe increases in moisture offshore, or in coastal areas, without seeing simultaneous increases inland. In MJ 2005, these negative moisture anomalies are centered over the eastern flank of the Sierra Madre Occidental, while there are slightly increases in moisture along the Pacific coast of Mexico. Fluxes from the Intra-Americas Sea correlate positively with rainfall over all of 

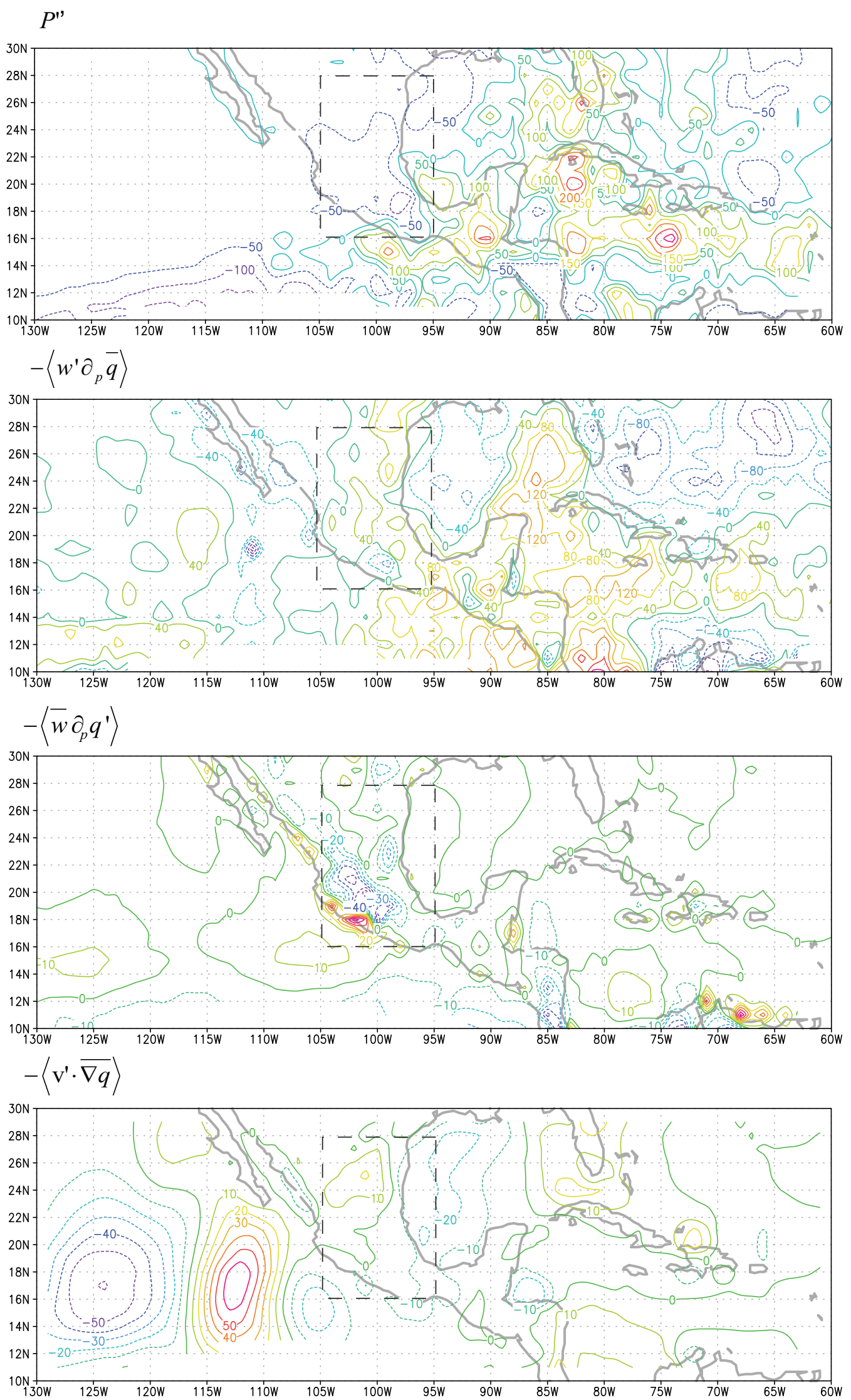

Fig. 10 The dominant terms in the anomalous moisture budget for MJ 2005, with rectangle showing averaging area for Fig. 9. Anomalies in W. $\mathrm{m}^{-2}$ 


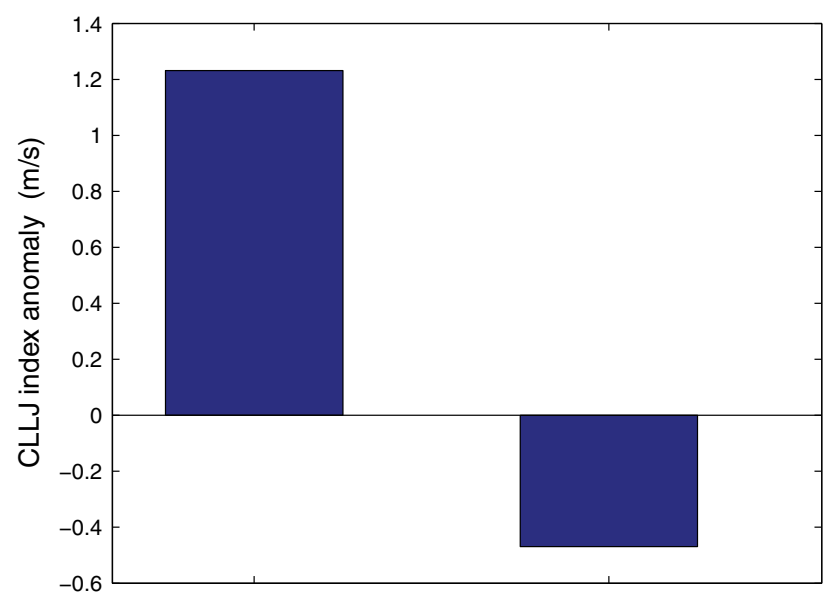

Fig. 11 Composite anomalies of the CLLJ index in the developing and decaying phase of warm ENSO events from 1979-2009

Mexico's land area, suggesting that Atlantic moisture sources contribute to boundary layer moisture even in the lee side of the Sierra Madre Occidental (Mestas-Nuñez et al. 2007). It is therefore possible that locally warm SST anomalies and resultant evaporative fluxes may result in moisture increases on the Pacific coast, while anomalous moisture fluxes from the Atlantic may still be responsible for the observed boundary layer drying.

The interaction of Mexico's topography with Atlantic moisture fluxes distinguishes Mexico's delayed response to ENSO from that of the Caribbean. Giannini et al. (2001) suggested that, absent the influence of an intensified North Atlantic High, warm Atlantic SSTs in the year following a warm ENSO event act to enhance boundary layer moisture and enhance convection. If our suggestion is correct, anomalously warm Atlantic SSTs may actually result in negative rainfall anomalies over Mexico as a consequence of diminished moisture transport across coastal mountain ranges. While as a first order approximation our hypothesis may describe the pattern we observe, a full evaluation of this hypothesis would require a detailed simulation of the precise influence of topography on winds. There are several factors, likely important in setting up the climatology of the low level jet, that we do not consider, such as the role of the mechanical forcing of topography in forcing its northward deflection over the Gulf of Mexico or even intensifying low-level winds, and the role of high elevation topography in setting up the thermal forcing behind winds.

\subsection{Interaction between the CLLJ and transient activity}

Thus far, we have only considered the importance of changes in the monthly mean circulation in driving observed ENSO-related rainfall anomalies. However, it is possible that changes to transient terms, integrated over the timescale of a month, might strongly contribute to the observed changes in the moisture budget. Mendez and Magaña (2010), for instance, argued that drought during the developing phase of warm ENSO events may be related to decreases in easterly wave activity over the IntraAmericas Sea (IAS). Formally assessing the role of wave disturbances would require analysis of daily data, and calculating the magnitude of transient terms in the anomalous moisture or moist static energy budget. The moist static energy budget could provide information about the important of transient versus mean flow terms in balancing the monthly mean changes in vertical velocity we observe in the developing phase of El Niño events (Chou et al. 2009). This analysis is beyond the scope of the current study. However, we attempt to assess changes to easterly wave activity by assessing changes in the monthly mean index of the CLLJ. Changes in mean atmospheric flow can generate conditions that favor or inhibit the development of transient eddies. Existing literature suggests a significant role for the low-level jet in generating the energy for transient disturbances in the IAS: barotropic instabilities generated by the jet tend to intensify wave activity over southern Central America and the eastern Pacific, but enhanced vertical wind shear and moisture divergence induced by the jet reduce wave activity over the Gulf of Mexico (Serra et al. 2010). Mendez and Magaña (2010) showed a strong negative correlation between easterly wave activity and the CLLJ. Since a stronger (weaker) CLLJ tends to correspond to less (more) easterly wave activity over the IAS, we use variability in the CLLJ as a proxy for the intensity of waves in the IAS that may contribute to precipitation over Mexico.

Based on composite analyses of the CLLJ index, we infer that easterly wave activity is weaker (stronger) in the developing (decaying) phase of warm ENSO events (Fig. 11). This is consistent with previous literature, and with the hypothesis that easterly wave disturbances may decrease in the IAS during the developing phase of ENSO, making a negative contribution to rainfall during this time period. However, in MJ, there is a weaker low-level jet over the Caribbean, which may act to enhance easterly wave activity. This is inconsistent with the idea that changes to easterly wave activity may explain the persistence of negative rainfall anomalies following peak El Niño events, as we would expect an enhanced contribution to rainfall from easterly waves. This suggests that changes to the mean monthly flow may in fact strongly contribute to negative rainfall anomalies. However, we emphasize that the CLLJ may not be the only mean-flow feature that contributes to transients, and that we cannot fully assess the relative importance of transient activity in contributing to negative precipitation anomalies without budget analyses that incorporate transient terms. 


\section{Summary and conclusions}

In this study, we clarified the intraseasonal evolution of the ENSO teleconnection to Mexican rainfall, and explored the atmospheric changes associated with El Niño-induced drought in Mexico. We found that, in Mexico, lead and lag correlations demonstrate evidence for drought in the summer of the year preceding the peak of warm SST anomalies in the eastern-central Pacific, as well as in the spring of the year following these warm SST anomalies. Our major findings resulted in an explanation for the changing intraseasonal spatial pattern of ENSO-induced negative rainfall anomalies, an evaluation of the anomalous subsidence versus land-sea thermal contrast mechanisms proposed for the developing phase of an El Niño event, as well as an understanding of the diverse mechanisms that may result in drought in the spring following a warm ENSO event.

We suggest that spatial heterogeneity in the strength of the relationship between ENSO and Mexican summer precipitation may best be explained as a result of changes in the location of mean convection. Caso et al. (2007) showed a latitudinal decrease in the strength of the correlation between summer rainfall anomalies and ENSO. Other studies confirmed that the ENSO teleconnection is weaker, if not opposite in sign, in northern versus southern Mexico (Hu and Feng 2002; Seager et al. 2009). We showed that the magnitude of individual stations' correlation with the Nino 3.4 index appears strongest in regions where we would expect climatologically strong gradients of moist static energy. This suggests that the ENSO teleconnection is strongest in regions of climatologically strong convection, and as the location of convection changes seasonally, so does the spatial extent of statistically significant correlations between the Niño 3.4 index and Mexican rainfall. Graef et al. (2000) daily precipitation climatology for Mexico as well as the early observations of Mosino-Aleman and Garcia (1974) showed the summer monsoonal rainfall follows the northward seasonal sweep of peak land surface temperatures. Given the seasonal northward sweep of peak moist static energy, regions in southern Mexico experience deep convection for a greater time period than those in northern Mexico, and therefore there is a greater time period during which the El Niñoinduced suppression of convective rainfall can influence southern Mexico.

Our detailed analysis of the 1997-1998 El Niño showed that, in this year, the dynamical feedback contributed strongly to negative precipitation anomalies. In both JAS 1997 and MJ 1998, the dynamical feedback is strongly negative, suggesting weakened upward motion over Mexico, resulting in weakened vertical advection and suppressed convection. Our results are similar to modeling studies: Seager et al. (2009) analyzed an ensemble of 100-day integrations ENSO-forced rainfall anomalies over Mexico, and found that the influence of the circulation change term (the dynamical feedback) on changes in stability outweighed the influences of changes in humidity in the anomalous moisture budget.

In JAS 1997, changes in onshore moisture advection, as might be expected if El Niño altered the land-sea thermal contrast, are much smaller than the dynamical feedback term. While we do observe anomalous winds that enhance negative precipitation anomalies along the eastern coast of Mexico in JAS 1997, these occur in the developing phase of El Niño before we would expect significant warming of Atlantic SSTs. This pattern may be linked to an enhanced interbasin gradient of SLP during El Niño events, which enhances moisture transport into the Pacific as a result of stronger easterly winds, increasing moisture divergence over coastal eastern Mexico.

The descent anomalies that occur during ENSO events are often termed the 'anomalous Walker circulation'. There are several mechanisms that could contribute to this circulation: one mechanism is the warming of the tropical troposphere, which causes temporary disequilibrium between boundary layer and free tropospheric equivalent potential temperature (Chiang and Sobel 2002). However, several processes may contribute to positive omega anomalies: specifically, in the anomalous moist static energy budget, circulation anomalies are balanced by changes in the gross moist stability of the atmosphere (i.e. the difference between vertically integrated dry static stability and moisture stratification), the net energy input to the atmosphere, the horizontal advection of moist static energy, as well as transient and non-linear terms (Chou et al. 2009; Zeng and Neelin 1999). Further analyses would therefore be necessary to understand the precise causes of descent anomalies.

Composite moisture budget anomalies on warm ENSO events between 1979 and 2007 show that, for the most El Niño events in this interval, the dynamic feedback accounts for a majority of the precipitation response in the developing phase of the ENSO event (i.e. year 0, prior to the peak SST anomalies). The situation is more complicated in the spring following a peak El Niño: despite a strong negative precipitation response in the majority of warm ENSO events, anomalous budget terms largely cancel each other out. This suggests heterogeneity in the mechanisms by which El Niño events cause delayed negative precipitation anomalies. Analyzing the dominant terms of the anomalous moisture budget in MJ 2005, we illustrate an alternative mechanism, apart from anomalous subsidence, by which lag effects of El Niño may induce drought. In MJ 2005, the moisture advection anomalies as a result of anomalous northerly and westerly winds reduce moisture transport along the Atlantic coast of Mexico, and the direct 
moisture effect shows strong drying in the boundary layer over inland Mexico. However, the direct moisture effect shows increases in boundary layer moisture off the east coast of Mexico. We note that a similar, albeit weaker, effect was also observed in MJ 1998. We tentatively suggest that the combined effect of anomalous winds and topography may result in less moisture transport inland onto the Mexican plateau. This is a mechanism that, to our knowledge, has not yet been considered in causing negative rainfall anomalies in Mexico. Note that this mechanism is distinct from the land-sea thermal contrast argument invoked to explain the ENSO teleconnection, as advection anomalies only appear to influence transport from the tropical Atlantic. This leads us to conclude that the interbasin gradient of SLP is likely more important than any land-sea thermal contrast in driving anomalous advection. In the absence of detailed model simulations, our hypothesis about the interaction of topography and anomalous winds remains an untested approximation, although it is derived from physical principles. It is also unclear why advection terms and the direct moisture effect dominate the delayed spring ENSO teleconnection in some years, while the dynamic feedback dominates in other years.

If this reduction in inland moisture transport does indeed play a role in negative precipitation anomalies, it has interesting implications for studies of inter-decadal changes in the ENSO teleconnection in Central America. It also suggests important ways in which highland Mexico's delayed rainfall response to ENSO differs from that of adjacent regions like the Caribbean: instead of rainfall increasing in response to warmer Atlantic temperatures, Mexico's highland areas may respond more strongly to anomalous wind patterns created by a reduced interbasin gradient of SLP. Several authors have noted that the strength of the ENSO teleconnection to various regions of Mexico in the mid-1970s, either as a result of changes in the phases of the PDO, AMO, or changes in the cooccurrence of positive phases of the NAO and warm ENSO events (Englehart and Douglas 2002; Hu and Feng 2008; Giannini et al. 2001). With respect to Atlantic changes, our proposed mechanism could offer an explanation of the nonstationarity of the ENSO teleconnection. Tropical North Atlantic warming has been shown to decrease moisture transport into northern Mexico and the central U.S., although the precise spatial pattern of this decrease differs between model simulations (Kushnir et al. 2010; Wang et al. 2008). It is possible that interdecadal changes to the strength of northward moisture transport may help to amplify or reduce the ENSO teleconnection to spring rainfall in Mexico. It is unclear how the PDO may influence this mechanism. Further research can clarify the way low-frequency changes in moisture transport interact with interannual variability.
Finally, there are several limitations to our approach: notably, in using monthly reanalysis fields we are unable to diagnose the contribution of changes in transient and nonlinear terms, which may be important in regions of Mexico where tropical storms or wave disturbances make up a larger proportion of summer rainfall. We note, however, that existing research suggests that tropical cyclones comprise at most $18 \%$ of total monthly precipitation between June and November in Mexico (Larson et al. 2005). We attempt to address changes in transient activity by using the strength of the CLLJ as a proxy for easterly wave activity in the IAS, although further analyses are needed to fully evaluate the role of transients. Other uncertainties in our budget calculations stem from imbalances in the NARR moisture budget and interpolation errors. Fortunately, comparison of our calculations to the native moisture flux convergence field from the NARR for the 1997-1998 ENSO event suggests that our calculations correctly approximate the sign and order of magnitude of moisture budget terms.

In summary, our results build on previous research on the teleconnection between ENSO and Mexican summer precipitation. We present evidence showing that drought occurs in Mexico in the year leading up to a peak El Niño as well as in the following spring. Our results are broadly consistent with the results of modeling studies that report precipitation reductions in the tropical Atlantic in response to anomalous convection in the eastern equatorial Pacific (Chiang and Sobel 2002; Lintner and Chiang 2007; Seager et al. 2009; Saravanan and Chang, 2000). Moisture budget analysis demonstrates that anomalous descent strongly contributes to negative precipitation anomalies in the summer before a peak El Niño event, and in some years contributes to negative precipitation anomalies in the spring following the peak event. In other years, however, anomalous advection due to anomalous winds and the direct moisture effect contribute to negative rainfall anomalies in the spring following a peak El Niño event. This effect may result from the interaction of the coastal mountain ranges in Mexico and weakened winds resulting from warm SSTs over the Intra-Americas Sea, although further testing is necessary to confirm this hypothesis. We note that this is distinct from the land-sea thermal contrast argument, in which we would expect changes in onshore moisture advection to play a dominant role on the Pacific coast in the developing phase of ENSO. In the developing phase of the 1997-1998 El Niño event, changes in onshore moisture advection make a very minor contribution to negative precipitation anomalies. In the decaying phase of El Niño, the fact that advection anomalies primarily only occur over the Intra-Americas Sea leads us to conclude that changes in the wind field primarily result from changes in the gradient of SLP between the Atlantic and Pacific, not a 
land-sea thermal contrast. We therefore conclude that anomalous subsidence, not a land-sea thermal contrast, is the dominant mechanism by which developing warm ENSO events induce negative precipitation anomalies in Mexico. Future work should focus on testing our hypothesis about the different mechanisms that may contribute to rainfall anomalies in the decaying phase of warm ENSO events. Further work can also help clarify the contribution of non-linear and transient terms, the factors that cause descent anomalies, and the interaction of ENSO with other modes of variability.

Acknowledgments This material is based upon work supported by the National Science Foundation Graduate Research Fellowship under Grant No. DGE 1106400.We acknowledge the developers of the Grid Analysis and Display System (GrADS); the MEXCDF, NetCDF, and SNCTOOLS packages for Matlab; and the M-Map package for Matlab. We thank Benjamin Lintner, Yuwei Liu, Andrew Friedman, and Roger Byrne for helpful discussions. We thank David Gochis and two anonymous reviewers, whose comments greatly improved this manuscript.

Open Access This article is distributed under the terms of the Creative Commons Attribution License which permits any use, distribution, and reproduction in any medium, provided the original author(s) and the source are credited.

\section{References}

Caso M, Gonzales-Abraham C, Escurra E (2007) Divergent ecological effects of oceanographic anomalies on terrestrial ecosystems of the Mexican Pacific coast. Proc Natl Acad Sci USA 104(25):10530-10535

Cavazos T, Hastenrath S (1990) Convection and rainfall over Mexico and their modulation by the southern oscillation. Int J Climatol 10:377-386

Chiang JCH, Lintner BR (2005) Mechanisms of remote tropical surface warming during El Nino. J Clim 18:4130-4149

Chiang JCH, Sobel AH (2002) Tropical tropospheric temperature variations caused by ENSO and their influence on the remote tropical climate. J Clim 15:2616-2631

Chou C, Neelin JD (2004) Mechanisms of global warming impacts on regional tropical precipitation. J Clim 17:2688-2701

Chou C, Neelin JD, Chen C, Tu J (2009) Evaluating the "rich-getricher" mechanism in tropical precipitation change under global warming. J Clim 22:1982-2005

Duran-Quesada AM, Gimeno L, Amador JA, Nieto R (2010) Moisture sources for Central America: identification of moistures sources using a lagrangian analysis technique. J Geophys Res 115 doi:10.1029/2009JD012455

Enfield DB, Mayer DA (1997) Tropical Atlantic sea surface temperature variability and its relation to El Niño Southern Oscillation. J Geophys Res Ocean 102:929-945

Englehart PJ, Douglas AV (2002) Mexico's summer rainfall patterns: an analysis of regional modes and changes in their teleconnectivity. Atmosfera 15(3):147-164

Giannini A, Cane MA, Kushnir Y (2001) Interdecadal changes in the ENSO teleconnection to the Caribbean region and the North Atlantic Oscillation. J Clim 14:2867-2879

Gochis DJ, Berberry EH (2011) Contributions from the North American monsoon experiment towards improved understanding and prediction of high impact weather and climate events. In: Chang C, Ding Y, Lau N, Johnson RH, Wang B, Yasunari T (eds) The global monsoon system: research and forecast, 2nd edn. World Scientific Publishing Company, Singapore, pp 159-182

Gochis DJ, Brito-Castillo L, Shuttleworth WJ (2007) Correlations between sea-surface temperatures and warm season streamflow in northwest Mexico. Int J Climatol 27:883-901

Graef F, Pavia EG, Reyes J (2000) A new temperature and precipitation climatology of stations in Mexico. EOS Trans Am Geophys Union 81:F744

Holton JR (2004) An introduction to dynamic meteorology, 4th edn. International Geophysics Series, Vol. 88. Elsevier Academic Press, Amsterdam

Hu Q, Feng S (2002) Interannual rainfall variations in the North American summer monsoon region: 1900-98. J Clim 15(10): 1189-1202

$\mathrm{Hu}$ Q, Feng S (2008) Variaion of the North American summer monsoon regimes and the Atlantic multidecadal oscillation. J Clim 21:2371-2383

Kushnir Y, Seager R, Ting M, Naik N, Nakamura J (2010) Mechanisms of tropical Atlantic SST influence on North American precipitation variability. J Clim 23:5610-5627

Larson J, Zhou Y, Higgins RW (2005) Characteristics of land falling tropical cyclones in the United States and Mexico: climatology and interannual variability. J Clim 18:1247-1262

Liebmann B, Blade I, Bond NA, Gochis D, Allured D, Bates GT (2008) Characteristics of North American summertime rainfall with emphasis on the monsoon. J Clim 21:1277-1294

Lintner BR, Chiang JCH (2007) Adjustment of the remote tropical climate to El Nino conditions. J Clim 20:2544-2557

Magaña VO, Vazquez JL, Perez JL, Perez JB (2003) Impact of El Niño on precipitation in Mexico. Geofis Int 42(3):313-330

Mendez M, Magaña V (2010) Regional aspects of prolonged meteorological droughts over Mexico and Central America. J Clim, Special U.S CLIVAR drought collection: 1175-1188

Mesinger F, DiMego G, Kalnay E (2006) North American regional reanalysis. Bull Am Meteorol Soc. doi:10.1175/BAMS-8-3-342

Mestas-Nuñez AM, Enfield DB, Zhang C (2007) Water vapor fluxes over the intra-Americas Sea: seasonal and interannual variability and associations with rainfall. J Clim 20:1910-1921

Mosino-Aleman PA, Garcia E (1974) The climate of Mexico. In: Bryson RAH, Hare FK (eds) Climates of North America, vol 2. Elsevier, New York, pp 345-405

Muñoz E, Busalaacchi AJ, Nigam S, Ruiz-Barradas A (2008) Winter and summer structure of the Caribbean low-level jet. J Clim 21:1260-1276

Nigam S, Ruiz-Barradas A (2006) Seasonal hydroclimate variability over North America in global and regional reanalyses and AMIP simulations: varied responses. J Clim 19:815-837

Peralta-Hernandez AR, Barba-Martinez LR, Magana-Rueda VO, Matthias AD, Luna-Ruiz JJ (2008) Temporal and spatial behavior of temperature and precipitation during the canicula (midsummer drought) under $\mathrm{El}$ Nino conditions in central Mexico. Atmosfera 21(3):265-280

Privé NC, Plumb RA (2007) Monsoon dynamics with interactive forcing. Part 1: axisymmetric studies. J Atmos Sci 64:1417-1430

Ruane AC (2010) NARR's Atmospheric water cycle components. Part 1: 20-year mean and annual interactions. J Hydrometeorol 11:1205-1219

Saravanan R, Chang P (2000) Interaction between tropical Atlantic variability and El Nino-southern oscillation. J Clim 13:21772194

Seager R, Ting M, Davis M, Cane M, Naik N, Nakamura J, Li C, Cook E, Stahle DW (2009) Mexican drought: an observational modeling and tree ring study of variability and climate change. Atmosfera 22(1):1-31 
Serra YL, Kiladis GN, Hodges KI (2010) Tracking and mean structure of easterly waves over the Intra-Americas Sea. J Clim 23:4823-4840

Smith TM, Reynolds RW, Peterson TC, Lawrimore J (2008) Improvements to NOAA's historical merged land-ocean surface temperature analysis (1880-2006). J Clim 21:2283-2296

Trenberth KE (1997) The definition of El Nino. Bull Am Meteorol Soc 78(12):2771-2777

Tucker DF (1999) The summer plateau low pressure system of Mexico. J Clim 12:1002-1015

Turrent C, Cavazos T (2009) Role of the land-sea thermal contrast in the interannual modulation of the North American Monsoon. Geophys Res Lett 36, doi:10.1029/2008GL036299

Wallace JM, Hobbs PV (2006) Atmospheric science: an introductory survey, 2nd edn. International Geophysics Series, Vol. 92. Elsevier Academic Press, Amsterdam
Wang C (2007) Variability of the Caribbean low-level jet and its relations to climate. Clim Dyn 29:411-422

Wang C, Lee S, Enfield DB (2008) Climate response to anomalously large and small Atlantic warm pools during the summer. J Clim 21:2437-2450

Wang B, Ding Q, Liu J (2011) Concept of global monsoon. In: Chang C, Ding Y, Lau N, Johnson RH, Wang B, Yasunari T (eds) The global monsoon system: research and forecast, 2nd edn. World Scientific Publishing Company, Singapore, pp 3-14

Xie S-P, Carton JA (2004) Tropical Atlantic variability: patterns, mechanisms, and impacts. In: Wang C, Xie SP, Carton JA (eds) Earth climate: the ocean-atmosphere interaction. Geophysical Monograph Series 147. AGU, Washington, pp 121-142

Zeng N, Neelin DJ (1999) A land-atmosphere interaction theory for the tropical deforestation problem. J Clim 12:857-871 